\title{
Erratum: Japan investors shun biotech
}

Ichiko Fuyuno

Nat. Biotechnol. 23, $516(2005)$

Nomura Research \& Advisory was incorrectly said to be "the research arm of brokerage giant Nomura Securities." It should have said it was "a subsidiary of Nomura Holdings."

\section{Erratum: Julian Thurston}

\section{Sabine Louët}

Nat. Biotechnol. 23, 517 (2005)

The interview suggested that Julian Thurston was a nonexecutive director of The Cancer Research Campaign. Although Julian Thurston served as a nonexecutive director of Cancer Research Campaign Technology Limited for several years and then of Cancer Research Ventures Limited (which undertook technology transfer services on behalf of The Cancer Research Campaign, now carried out by Cancer Research Technology Limited) until September 2002, he was never a director or trustee of The Cancer Research Campaign. The Cancer Research Campaign merged with the Imperial Cancer Research Fund in February 2002 to form Cancer Research UK. In addition, the text mentions that Julian Thurston started his career as general counsel for what was once the flagship of UK biotech-Celltech, now part of Belgian mid-sized pharma company UCB. It should have read "Julian Thurston started his career at McKenna \& Co. and during most of the 1980s with his team provided all the legal support to the firm's first biotech client, Celltech, once the flagship of UK biotech, now part of Belgian mid-sized pharma company UCB."

\section{Erratum: Navigating an ethical patchwork—human gene banks}

\section{Karen J Maschke}

Nat. Biotechnol. 23, 539-545 (2005)

In Table 1, page 540, the source of funding for the Singapore Tissue Network was given as the "Singapore Biomedical Research Council, Agency for Science, Technology and Research, Ministry of Health and the Genome Institute of Singapore." It should have read the "Singapore's Biomedical Research Council of the Agency for Science Technology and Research." In addition, the network does not, as stated, collect "genomic information from Singapore population groups"; the network collects and distributes research biospecimens including tissues and DNA with informed consent.

\section{Erratum: Biotech hits regulatory doldrums}

Stacy Lawrence

Nat. Biotechnol. 23, 644 (2005)

On the $x$-axis of the graph "Approval times for priority and standard BLAs," the years should have ranged, from left to right, from 1995 to 2004. In addition, the colors of all but the last number are incorrect. The upper numbers should have been brown and the lower blue. The corrected graph is below.

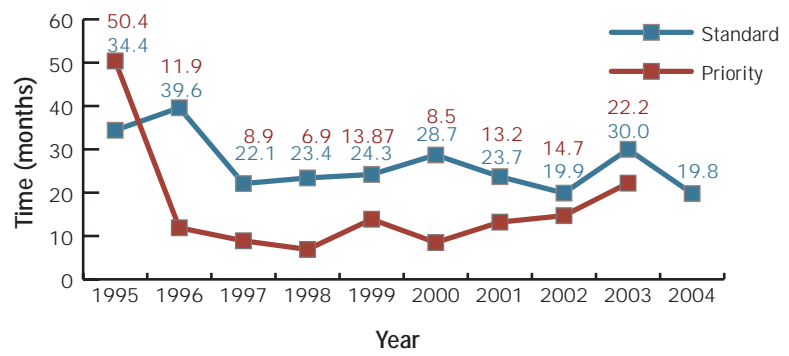

